\title{
A Imagem do Trabalho: um Estudo Qualitativo Usando Fotografia em Grupos Focais
}

\author{
Sônia Maria Guedes Gondim \\ Girleide Novaes Feitosa \\ Marina Chaves
}

\begin{abstract}
Resumo
A foto é um tipo de imagem usada para investigar os significados atribuídos pelo homem, por meio de técnicas de registro, feedback, fotografia do autor, ou modelo (Neiva-Silva \& Koller, 2002). O objetivo da pesquisa foi usar fotos como modelo para analisar a imagem atual do trabalho. Os 50 participantes foram divididos em 10 grupos focais de atuação diversa no mercado de trabalho: formação, seleção, profissionais de nível superior, e profissionais formais e informais pouco qualificados. Foram usadas 36 fotos coloridas e 96 fotos preto e branco de pessoas em situação de trabalho para serem escolhidas pelos participantes. Os participantes anotaram individualmente os números das fotos escolhidas e registraram em poucas palavras o que havia de significativo em cada uma. Os registros foram investigados por técnicas de análise de conteúdo temático. A análise indutiva identificou três categorias (temas) de respostas: i) macrocontexto do trabalho, ii) atributo do trabalhador e iii) setor da economia. Concluiu-se que a imagem do trabalho está fortemente associada a discussões de macrocontexto e de atributos do trabalhador, independentemente do grupo. Os profissionais de nível superior e de formação centram-se em argumentos e reflexões de macrocontexto. Os pouco qualificados distinguem o trabalho real (sobrevivência) do trabalho ideal (escolarizados).
\end{abstract}

Palavras-chave: imagem do trabalho; fotografias; macrocontexto do mercado; atributos do trabalhador; setor.

\begin{abstract}
Photography is a kind of image to investigate the meanings imparted by man, through the use of recording techniques, feedback, self-portrait or model (Neiva-Silva \& Koller, 2002). The aim of this research is to analyze current image of work using photography as a model. The 50 subjects were divided into ten focus groups according to the nature of their occupation: professionals responsible for either training or recruiting labor force, those holding a higher-level degree, as well as under qualified workers from both informal and formal segments. The subjects were to choose from 132 pictures ( 36 colorful and 96 black \& white) that depicted working situations. Participants had then to individually write down the numbers corresponding to the pictures they had chosen and briefly say how meaningful each of them was. Answers were analyzed through thematic content analysis techniques. The inductive analysis identified three thematic category answers: i) the macro context of work, ii) worker attributes and iii) economy sector. One of the conclusions was that work image is strongly associated with macro context issues and worker attributes although, regardless of group. Human Resource professionals and those holding a degree focus on arguments and reflections macro context. The professionals with low qualification maintain a distinction between real work (which guarantees survival) and the ideal one (developed by qualified professionals).
\end{abstract}

Key words: work image; photography; macro context of work; worker attributes; sector. 
A fotografia como recriação da realidade, como simulacro que é ou não é, ao mesmo tempo, o objeto real, a fotografia no que mostra e o que dissimula, como conhecimento dissociado da experiência, redefine a própria realidade (Ciavatta, 2002, p. 16).

A imagem mental é um fenômeno psicológico que permite ao homem representar os acontecimentos e os objetos à sua volta e registrá-los na memória. Esta representação pode assumir formato semelhante ou diferente do objeto ou evento ao qual se refere, como pode também ser compartilhada socialmente ou visualizada por apenas uma pessoa. Dito em poucas palavras, a imagem mental é uma forma de representação visual, que influencia a maneira como a pessoa percebe, reage e interage com o mundo, e quando esta imagem assume a forma de uma foto, adquire a função de mediação, tornando necessária alguma descodificação para a apreensão do sentido dado por aqueles que lhe atribuem significado (Leite, 1993).

A importância de se estudar a imagem em investigação científica está no fato de ela reunir muitas informações integradas em um todo organizado, o que não se consegue obter por meio da simples descrição verbal. De acordo com Meleiro (1997), quando os cientistas desejam apreender a realidade, usando outros recursos que não a mera enunciação verbal, recorrem a abstrações mentais derivadas das percepções cotidianas, já que elas são construídas a partir da interação do sujeito com essa realidade.

A imagem é uma modalidade de expressão humana bem mais antiga do que a palavra; mas, ao contrário desta última, infelizmente, tem sido subestimada em investigações científicas. O que causa estranheza é que a imagem está integrada à visão, um dos órgãos dos sentidos mais importantes da apreensão humana da realidade. $\mathrm{O}$ descaso com este fato é um empecilho para o acesso à riqueza de informações passíveis de serem extraídas deste ângulo de análise. Cada ser humano se depara, no cotidiano, com imagens multifacetadas sobre as quais é convidado a dar uma resposta valorativa, principalmente de atração ou repulsão, cuja investigação permitiria compreender os significados das associações mentais e emoções delas suscitadas. Investigar as imagens do trabalho na atualidade, por exemplo, irá ajudar a compreender aspectos centrais da construção de sentidos das relações do homem com o mundo do trabalho, em que estão envolvidos personagens (quem exerce atividades), objetos (conteúdo das atividades e tarefas) e cenários (em que locais e lugares as atividades de trabalho ocorrem). A apreensão desses elementos integrados na imagem permitirá fazer inferências sobre o nível de compartilhamento e de diferenciação da visão do 
mundo do trabalho para determinado grupo social ou sociedade (Santaella \& Nöth, 2005). Este foi um dos principais objetivos ao desenvolver a pesquisa que será, em parte, discutida neste artigo. Partiu-se da premissa de que, dependendo do lugar que o grupo social ocupa no cenário mais amplo do mundo do trabalho, ele sustenta imagens que mantêm semelhanças e diferenças com outros grupos, a depender do papel fundamental que este mesmo grupo exerce nesse contexto mais abrangente.

As variadas modalidades de registro de imagem (fotos, desenhos, pintura, escultura etc.) oferecem amplo leque de possibilidades para a apreensão da representação imagética das pessoas em relação aos eventos ou objetos que as cercam. Para Loizos (2002), a imagem é um poderoso registro dos acontecimentos e das ações no tempo e no espaço, embora o uso em pesquisa ainda seja limitado. Um obstáculo é que a imagem constitui apenas uma forma de representação da realidade, e como toda forma de representação, nem sempre funciona como um espelho. Áries (1981) interpretou as sociedades tradicionais a partir da análise de pinturas da renascença e argumentou a favor de um novo lugar ocupado pela criança e a família nas sociedades industriais. Ciavatta (2002) reuniu fotografias de condições de vida e de trabalho de trabalhadores do Rio de Janeiro, no período de 1900 a 1930, com o objetivo de analisar o mundo do trabalho, especialmente pelo ângulo da alienação. É bem possível que os padrões estéticos dos artistas que pintaram os quadros ou fotografaram os eventos em ambos os estudos mencionados acima, somados ao fato de eles terem retratado situações reais ou fictícias, sejam aspectos importantes que repercutem nas interpretações feitas destas imagens, aproximando-as ou distanciando-as da situação cotidiana que porventura seus autores pretenderam retratar. São esses fatores que tornam vulnerável o processo de inferência de significados (Loizos, 2002), contribuindo para que um mesmo evento, supostamente real, possa gerar imagens mentais distintas nas pessoas. Isto, no entanto, é uma restrição inerente a toda forma de representação, que depende de interpretação para a apreensão do sentido dado no referido contexto. Em sendo assim, toda análise apresenta uma possibilidade de interpretação, passível de ser questionada aos olhos de outro observador que esteja mais atento a outro ângulo da mesma imagem.

O uso da fotografia em pesquisas no campo da psicologia não é recente, porque, segundo Neiva-Silva e Koller (2002), ela está sendo usada há mais de cem anos, com o principal objetivo de investigar os significados relacionados a este tipo de formatação de imagem. As técnicas usadas para apreensão desses significados podem ser de quatro modalidades: registro, feedback, fotografia do autor e modelo. 
Ao se valer da imagem como forma de registro, o que se pretende é documentar algumas ocorrências reais, para que seja avaliada a repercussão de seu conteúdo nas pessoas. Um exemplo é o do pesquisador que pretende estudar o impacto de fotos reais de acidentes de trabalho nos empregados de uma indústria de aço. Seu objetivo poderia ser o de dar subsídios para a elaboração de projetos de intervenção e de prevenção de acidentes. Quando o foco da técnica está em usar a imagem como feedback para a própria pessoa (que esteja representada na foto), o que importa é retratá-la em diversos contextos (interagindo com outros, exercendo atividades no trabalho, cuidando de filhos etc.); a foto irá servir de insumo para a auto-reflexão e autoconscientização de como ela atua nestes cenários. É fácil concluir que esta técnica é bastante usada em abordagens clínicas e em pesquisas qualitativas, haja vista que ambas se preocupam com o autoconhecimento e o conhecimento da realidade, a partir da percepção do sujeito, assim como com a mudança pessoal e social.

A terceira técnica mencionada por Neiva-Silva e Koller (2002), a fotografia do autor, tem como foco a pessoa que fotografa (quem registra uma imagem). O objetivo está em investigar como cada um percebe e retrata o mundo. Para isso, a pessoa é solicitada a fotografar livremente e o foco de análise recai no tema escolhido (lugar, objeto de representação, cenário etc.) ou no autor da foto (características do autor versus tema escolhido). Um pesquisador pode estar interessado em investigar a imagem que as pessoas têm da pobreza, e, então, solicitar aos participantes que fotografem tudo aquilo que a representa. A pobreza, por exemplo, poderia estar representada em fotos de meninos de rua, de favelas, de regiões áridas etc., e de algum modo estaria relacionada também ao perfil psicológico do autor da foto.

O modelo é a quarta modalidade técnica de uso da fotografia na pesquisa psicológica, cujo foco passa a ser o observador. A escolha das fotos a serem analisadas obedece a critérios do pesquisador, que almeja avaliar as percepções dos observadores em relação às fotos apresentadas como modelo. Tais fotos retratariam situações reais ou fictícias.

Torna-se oportuno esclarecer aqui que, nesta parte inicial do artigo, se privilegiou a discussão relativa às possibilidades do uso da fotografia para investigar imagens do trabalho, ao invés de apresentar uma revisão teórica sobre a imagem ou imagens do trabalho. Deixou-se de fora, por exemplo, Morgan (1996), autor que associou imagem e metáfora e as considerou não só como formas de representação da realidade organizacional, mas como estruturas de pensamento que repercutem de modo decisivo nas estratégias de ação adotadas por gestores. Sem dúvida, trata-se de uma opção consciente 
das autoras, visto que tais descrições poderiam ser estimuladoras para que outros pesquisadores viessem a usar o recurso da fotografia para investigar diversos aspectos de importância no campo das organizações do trabalho e áreas afins.

Há uma crença compartilhada de que, ao longo da história humana, a relação do homem com o trabalho se tem mostrado ambivalente, visto que, ao mesmo tempo que o trabalho é percebido como um fardo necessário para garantir a sobrevivência econômica, é valorizado pela sua importância para a satisfação pessoal e a construção da identidade social. Outra crença compartilhada, a persistir no tempo, é a de que há dois tipos de trabalho de qualidades distintas: o trabalho braçal, desvalorizado, e que se apresenta como a única alternativa para aqueles que possuem baixo status social, e o trabalho intelectual, privilégio dos escolarizados (Arendt, 1981; Battaglia, 1958; Brandão, 2002; Gondim, 2001). Os dados e argumentos a serem apresentados e discutidos nas outras seções permitem a visualização desta relação vivida por alguns como ambivalente e por outros como dicotômica.

A rigor, o principal objetivo deste artigo é o de colocar em destaque o emprego da fotografia na investigação científica, ilustrando-o a partir de uma pesquisa exploratória qualitativa que fez uso deste recurso técnico. Assim, a partir de agora o foco do artigo recairá na descrição desta pesquisa, incluindo o uso do recurso da fotografia nos grupos focais para fins de coleta de dados e ainda discorrendo sobre a análise dos resultados.

\section{MÉTOdO}

A premissa, ponto de partida para o desenho da pesquisa, foi a da existência de similaridades e diferenças na imagem que os grupos sociais constroem em relação ao trabalho e, em complementação a ela, a de que tais diferenças e similaridades se tornariam mais visíveis se as pessoas fossem agrupadas por meio de algum critério comum que as unisse, como, por exemplo, o papel que ocupam no cenário do mundo do trabalho, sendo convidadas a discutir em conjunto sobre este tema. Neste caso, se o papel principal for o de ser o responsável pelo processo de formação do futuro profissional, tais como o professor de ensino superior, a imagem do trabalho estaria de algum modo sendo influenciada pela sua experiência como formador. Do mesmo modo, se o principal papel for o de selecionador, por atuar em processos de recrutamento e seleção de pessoas para outras empresas e organizações, tal fato geraria algum impacto na imagem do trabalho. É fato que uma pessoa pode exercer ao 
mesmo tempo dois ou mais papéis, como ser professor e profissional especializado em processos de recrutamento e seleção, mas procurou-se atenuar o impacto de outros papéis sociais e profissionais, ao agrupar as pessoas levando em conta o papel predominante, na expectativa de que isso repercutisse na discussão dentro dos grupos focais.

\section{Seleção das Fotos para Modelo}

$\mathrm{Na}$ pesquisa foram utilizadas fotos coloridas e preto e branco de pessoas em situações de trabalho. O motivo de oferecer modelos coloridos e preto e branco foi consequiência da constatação de que a versão em português do teste psicológico BBTr-Br (versão masculina), bastante usado na orientação profissional de adolescentes, contém somente fotos preto e branco (no total 96) que retratam situações de trabalho em ocupações tradicionais. Ora, se o objetivo era o de investigar a imagem do trabalho na atualidade, embora não se deva ignorar que uma imagem possa manter-se inalterada ao longo do tempo, seria necessário incluir fotos coloridas que retratassem contextos ocupacionais atuais e que incluíssem mulheres. Para tal, foram selecionadas fotos coloridas de pessoas em situações de trabalho em diversas publicações de circulação nacional freqüientemente comercializadas em bancas de revista. Os critérios adotados para a seleção das fotos coloridas foram os seguintes: presença de mulheres e homens, brancos e negros, em contextos de trabalho de uso de novas tecnologias, ocupações de baixa qualificação e de alta qualificação, assim como contextos de atuação em diversos setores: agricultura, indústria, comércio, turismo, artes etc. No total foram selecionadas 36 fotos que o grupo de pesquisa acreditou ter obedecido a tais critérios de diversidade. A preocupação não foi a de equivaler à quantidade das fotos do teste BBTr-Br, aliás considerado um número excessivo, mas oferecer modelos alternativos de escolha que retratassem situações de trabalho na atualidade.

\section{O Uso de Grupos Focais como Estratégia de Pesquisa Qualitativa}

Os grupos focais constituem uma estratégia de abordagem de pesquisa que permite investigar um fenômeno a partir das trocas verbais entre participantes de um grupo ao serem apresentados tópicos para discussão (Gondim, 2002; Morgan, 1997).

As fotos foram, então, apresentadas aos participantes na fase inicial de discussão de 10 grupos focais homogêneos, cujos participantes eram convidados a escolher até três fotos (coloridas e preto e branco) que representassem a imagem que 
tinham do trabalho na atualidade, registrando por escrito o que avaliavam como mais significativo em cada uma delas.

\section{Participantes}

Os 50 participantes pertenciam a diversas categorias profissionais classificadas como de formadores, qualificadores, profissionais de nível superior e também de baixa qualificação, tanto do mercado formal, quanto informal. Partiu-se da premissa de que professores, que são responsáveis pela formação de futuros profissionais; profissionais de diversas áreas; trabalhadores de baixa qualificação e nível de escolaridade, que exercem suas atividades no mercado formal e informal, assim como profissionais de recursos humanos e de qualificação, que se especializam em seleção de pessoas para o mercado e estão mais familiarizados com as políticas de qualificação do trabalhador, visualizam o mundo do trabalho ${ }^{(1)}$ conforme a posição predominante que ocupam nele. Como mencionado na primeira parte deste artigo, não se tem dúvida de que uma pessoa exerça vários papéis no cenário no mundo do trabalho, mas procurou-se privilegiar aquele papel que seria mais representativo da experiência profissional do participante. Não foi por acaso que os participantes foram intencionalmente selecionados. Apostou-se no fato de que como haveria discussão nos grupos, as características comuns trariam à tona a perspectiva dominante de sua visão do trabalho, que estaria apoiada na experiência que os unia em torno do exercício do seu papel mais significativo no contexto de trabalho. Isto tem sentido, na medida em que somos capazes de identificar com certa facilidade a que grupo social e profissional um conjunto de pessoas pertence, simplesmente ao acompanharmos, em uma mesa de bar localizada ao lado, a conversa que os membros travam entre si, pois o grupo de pertencimento repercute no tema escolhido, na linguagem e jargões utilizados, assim como nos argumentos a favor ou contra determinado assunto.

A Tabela 1 especifica as características gerais dos 50 participantes, cujas idades variavam de 24 e 60 anos, e sua distribuição nos 10 grupos focais. 


\section{Tabela 1: Caracterização dos Participantes dos Grupos Focais}

\begin{tabular}{|c|c|c|c|c|}
\hline \multirow[t]{2}{*}{ CATEGORIAS DOS GRUPOS FOCAIS } & \multicolumn{2}{|c|}{ SEXO } & \multirow{2}{*}{ ESPECIFICAÇÕES } & \multirow[t]{2}{*}{$\mathbf{N}$} \\
\hline & $\mathbf{F}$ & $\mathbf{M}$ & & \\
\hline 1. Profissionais de Recursos Humanos & 2 & 1 & 3 atuavam em consultorias & 3 \\
\hline 2. Professores Universitários de Ciências Humanas & 4 & 2 & $\begin{array}{l}4 \text { da rede pública } \\
2 \text { da rede privada }\end{array}$ & 6 \\
\hline 3. Professores Universitários de Ciências Humanas & 4 & 3 & $\begin{array}{l}3 \text { da rede pública } \\
4 \text { da rede privada }\end{array}$ & 7 \\
\hline 4.Professores Universitários de Ciências Exatas & 2 & 2 & $\begin{array}{l}2 \text { da rede pública } \\
2 \text { da rede privada }\end{array}$ & 4 \\
\hline 5.Profissionais da área de Ciências Humanas & 5 & 2 & $\begin{array}{l}4 \text { da rede pública } \\
3 \text { da rede privada }\end{array}$ & 7 \\
\hline 6.Profissionais da área de Ciências Exatas & 1 & 2 & $\begin{array}{l}1 \text { que atua na área } \\
2 \text { não atuam na área }\end{array}$ & 3 \\
\hline 7.Profissionais da área de Saúde & 3 & 6 & $\begin{array}{l}6 \text { que atuam na área } \\
3 \text { não atuam na área }\end{array}$ & 9 \\
\hline $\begin{array}{l}\text { 8.Profissionais que atuam em qualificação do } \\
\text { trabalhador }\end{array}$ & 1 & 3 & $\begin{array}{l}1 \text { que atua no terceiro setor } \\
3 \text { no setor público }\end{array}$ & 4 \\
\hline $\begin{array}{l}\text { 9.Profissionais de baixa qualificação do mercado } \\
\text { formal }\end{array}$ & 2 & 2 & $\begin{array}{l}\text { Auxiliar administrativo, } \\
\text { empregada doméstica, auxiliar } \\
\text { de serviços gerais, mestre de } \\
\text { obras }\end{array}$ & 4 \\
\hline $\begin{array}{l}\text { 10.Profissionais de baixa qualificação do mercado } \\
\text { informal }\end{array}$ & 1 & 2 & $\begin{array}{l}\text { Taxista, pintor } \\
\text { (multifuncional), faxineira }\end{array}$ & 3 \\
\hline Total & & & & 50 \\
\hline
\end{tabular}

Cabe esclarecer que no processo de escolha dos participantes se procurou garantir algum nível de heterogeneidade, visando a facilitar a emergência de pontos de vista opostos que estimulassem o debate e o processo de discussão. Assim, o grupo de profissionais de recursos humanos contou com três participantes que atuavam em empresas de consultoria de portes diferenciados, enquanto o grupo de professores das três áreas contou com a participação daqueles que atuavam no setor público e no privado. Nos grupos de profissionais de diversas áreas, a característica comum era a de que haviam tido a mesma formação profissional, enquanto a heterogeneidade foi garantida pelo fato de alguns atuarem em outra área. No grupo dos profissionais de qualificação, considerados especialistas em programas de qualificação do trabalhador, um atuava em uma organização do terceiro setor e os outros três em programas vinculados a políticas públicas. Por último, os profissionais de baixa escolarização e qualificação foram divididos em dois grupos, os que tinham carteira assinada (auxiliar administrativo, empregada doméstica, mestre de obras e auxiliar de serviços gerais) e os prestadores de serviços (taxista, faxineira e um pintor, que a rigor fazia biscates de diversos tipos).

\section{Procedimentos de Contato com os Participantes}

Para a composição dos 10 grupos focais foram adotados os seguintes procedimentos: i) contato telefônico ou face a face por indicação de terceiros; ii) envio por e-mail do projeto de pesquisa, no caso de interesse em participar; iii) 
novo contato para confirmação da participação nos grupos focais e instrução do local de realização e iv) último contato no dia anterior à realização do grupo focal, para confirmação de presença.

\section{Procedimentos de Condução dos Grupos Focais}

Os grupos focais tiveram início com esclarecimentos da moderadora (primeira autora) sobre os objetivos da pesquisa e as regras para a discussão. Utilizou-se um roteiro de dois tópicos: i) imagem do trabalho atual e ii) habilidades requeridas do trabalhador no contexto de trabalho. Para abordar o primeiro tópico, objeto de análise deste artigo, distribuíram-se na mesa as 36 fotos coloridas de pessoas em situação de trabalho. Essas fotos foram coladas em papel cartão e numeradas no verso. A cada participante foi pedido que individualmente, e sem que conversassem com os demais membros do grupo, escolhesse até três fotos que representassem a imagem do trabalho na atualidade. Os participantes, então, deveriam registrar em papel os números das fotos escolhidas e ao seu lado, e em poucas palavras, o que havia de significativo em cada uma delas. As fotos, então, eram recolhidas e 96 fotos preto e branco ${ }^{(2)}$ de pessoas em situação de trabalho, também numeradas no verso, eram distribuídas sobre a mesa para em seguida se repetir a instrução. Concluídas essas etapas deu-se início ao processo de discussão em grupo a partir das fotos preto e branco que já estavam sobre a mesa. Após a primeira rodada de apresentação e discussão, foi feito o mesmo procedimento com as fotos coloridas. Cada participante deveria mostrar aos outros as fotos escolhidas e dizer as razões da sua escolha. Os resultados analisados neste artigo se restringem à escolha de fotos coloridas e preto e branco e os registros feitos em papel por cada participante, eventos que ocorreram na fase inicial dos grupos focais. As discussões desencadeadas a partir destas escolhas não serão, portanto, analisadas neste artigo.

\section{Procedimentos e Análise dos Resultados}

O foco de análise recaiu nas anotações que os integrantes dos grupos fizeram ao lado do número das fotos escolhidas. Para fins de procedimentos de análise deste material escrito foi usada a técnica de análise temática de conteúdo. A análise de conteúdo é um conjunto de técnicas que tem por finalidade a interpretação dos sentidos e dos significados de diversas manifestações humanas apresentadas sob a forma de discursos, falas, fotos, pinturas, esculturas, documentos escritos, transcrições, narrativas etc. (Bardin, 1979; Bauer, 2002; Iñiguez, 2004; Smith, 2000). As diversas técnicas de análise de conteúdo têm como objetivo também organizar, ordenar, agrupar e classificar o material sob análise em categorias que expressem, de modo simplificado, os conjuntos de unidades de registros significativos relacionados ao problema ou ao objeto de estudo da pesquisa. Há pelo menos duas técnicas de análise de conteúdo, que podem ser mencionadas para fins de ilustração. 
A técnica de dicionário, que consiste em agrupar as unidades de registro (palavras) pela similaridade (sinonímia) de significados e outras conotações; e a técnica correlacional, também chamada temática, que consiste no agrupamento de unidades de registro (palavras, por exemplo) que, apesar de isoladamente terem significados diferenciados, ao serem tratadas em conjunto (frases) fazem referência ao mesmo tema. A opção recaiu sobre esta última, ao eleger o tema como foco de análise. Os registros feitos por meio de palavras isoladas ou frases curtas permitiu identificar indutivamente três categorias temáticas: i) macrocontexto; ii) atributos da pessoa do trabalhador; e iii) setor da economia ou categoria profissional. Na categoria temática 'macrocontexto' foram agrupados aqueles dizeres que faziam menção a questões mais abrangentes do mundo do trabalho, sem levar em conta a ocupação ou setor de economia ilustrado na foto. Inseriam-se nesta categoria referências à tecnologia e seus efeitos no mundo do trabalho, às características gerais de qualquer trabalho na atualidade, às relações sociais de trabalho e às questões de gênero e sua inserção no mercado de trabalho. Na categoria 'atributos' da pessoa do trabalhador foram reunidos os registros relativos às habilidades, às atitudes e aos estados afetivos exigidos do trabalhador no mercado de trabalho atual. Embora os atributos mencionados pelos participantes não hajam sido focados em uma ocupação específica e, portanto, podendo ser classificados como registros da categoria macrocontexto, a especificidade da categoria de atributos consistiu na enumeração de características que se impõem ao trabalhador para melhorar suas chances de concorrer no mercado de trabalho. Na terceira e última categoria, setor da economia ou categoria profissional, foram reunidas referências dos participantes aos setores da economia ou profissão ilustrados nas próprias fotos. Dito de outro modo, o que chamou a atenção do participante ao escolher a foto foi o setor, a área da economia ou a profissão nela retratada.

\section{Apresentação e Discussão dos Resultados}

O primeiro aspecto a ser considerado é o de que houve dispersão muito grande nas escolhas das fotos feitas pelos participantes, o que é previsível pelo número expressivo de fotografias disponíveis para escolha (36 coloridas e 96 preto e branco). Ainda que tenham sido adotadas medidas de precaução, ao orientar os participantes a escolherem no máximo três fotos de cada agrupamento (coloridas e preto e branco), no final deparou-se com número elevado de fotos selecionadas. A alternativa foi categorizar os registros por afinidade de significados temáticos e depois relacionar os temas com as diversas fotos escolhidas pelos participantes, ao invés de partir da frequiência de escolha das fotos e identificar os temas nelas relacionados. Assim, as fotos mencionadas nos quadros apresentados neste artigo não devem ser interpretadas como sendo as mais escolhidas pelos integrantes dos grupos focais, mas como ilustrações representativas dos temas (conteúdos) mais evidenciados. 
O Quadro 1 apresenta os temas abordados pelos grupos de profissionais de recursos humanos e de qualificação. Para os profissionais de recursos humanos as representações de macrocontexto de trabalho foram suscitadas pela foto de uma mesa em que estão reunidos vários políticos, um consultório médico oftalmológico com equipamentos modernos e um paciente sendo atendido em cama de hospital. Tais fotos fizeram emergir a questão da necessidade de acordos entre patrões e empregados, a tecnologia e a humanização.

O macrocontexto para os profissionais de qualificação foi representado pelas fotos de uma equipe técnica de televisão e de um apresentador de sucesso, homens trabalhando em uma linha de produção industrial e outros tantos trabalhando em uma bolsa de valores. Os temas associados foram: a gestão participativa, a inovação, a substituição do homem pela máquina e a pressão para a tomada de decisão.

\section{Quadro 1: Profissionais de Recursos Humanos e Profissionais de Qualificação}

\begin{tabular}{|c|c|c|c|c|c|}
\hline \multicolumn{3}{|c|}{ Profissionais de Recursos Humanos } & \multicolumn{3}{|c|}{ Profissionais de Qualificação } \\
\hline $\mathbf{C}$ & Descrição da Foto & Tema & $\mathrm{C}$ & Descrição da Foto & Tema \\
\hline \multirow{3}{*}{ 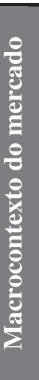 } & $\begin{array}{l}\text { Uma mesa oval em torno da } \\
\text { qual estão sentados vários } \\
\text { políticos (foto } 7 \mathrm{C} \text { ) }\end{array}$ & $\begin{array}{l}\text { Processo } \\
\text { Acordos } \\
\text { empresa/empre- } \\
\text { gado }\end{array}$ & \multirow{4}{*}{ 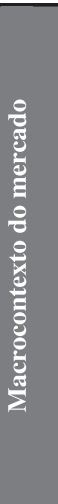 } & $\begin{array}{l}\text { Equipe técnica reunida nos } \\
\text { bastidores de um canal de TV } \\
\text { (foto } 22 \mathrm{C} \text { ) }\end{array}$ & $\begin{array}{l}\text { Gestão } \\
\text { participante }\end{array}$ \\
\hline & $\begin{array}{l}\text { Oftalmologista em seu } \\
\text { consultório junto a } \\
\text { modernos equipamentos } \\
\text { (foto } 4 \mathrm{C} \text { ) }\end{array}$ & Tecnologia & & $\begin{array}{l}\text { Homens com equipamento de } \\
\text { segurança trabalhando em } \\
\text { linha de produção (foto } 3 \mathrm{C} \text { ) }\end{array}$ & $\begin{array}{l}\text { Substituição do } \\
\text { homem pela } \\
\text { máquina }\end{array}$ \\
\hline & $\begin{array}{l}\text { Um homem cuidando de } \\
\text { um paciente que está numa } \\
\text { cama de hospital (foto } 3 \\
\text { PB) }\end{array}$ & Humanização & & $\begin{array}{l}\text { Homens em uma bolsa de } \\
\text { valores (foto } 16 \mathrm{~PB} \text { ) }\end{array}$ & $\begin{array}{l}\text { Pressão para } \\
\text { decisão }\end{array}$ \\
\hline \multirow{4}{*}{ 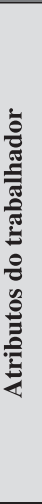 } & $\begin{array}{l}\text { Um recepcionista em um } \\
\text { balcão de hotel atendendo a } \\
\text { um telefonema (foto } 40 \mathrm{~PB} \text { ) }\end{array}$ & Comunicação & & $\begin{array}{l}\text { Sílvio Santos em seu } \\
\text { programa (foto } 60 \mathrm{~PB} \text { ) }\end{array}$ & $\begin{array}{l}\text { Inovação } \\
\text { (programa } \\
\text { líder de } \\
\text { audiência) }\end{array}$ \\
\hline & $\begin{array}{l}\text { Um homem fazendo um } \\
\text { arranjo de flores (foto } \\
41 \mathrm{~PB} \text { ) }\end{array}$ & Criatividade & \multirow{3}{*}{ 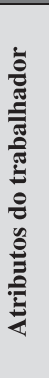 } & $\begin{array}{l}\text { Uma mulher sentada em uma } \\
\text { mesa onde há vários livros, } \\
\text { folhetos de viagem e um } \\
\text { computador (foto } 30 \mathrm{C} \text { ) }\end{array}$ & $\begin{array}{l}\text { Aperfeiçoa- } \\
\text { mento contínuo }\end{array}$ \\
\hline & $\begin{array}{l}\text { Duas moças em frente ao } \\
\text { espelho tendo aula de balé } \\
\text { com um professor (foto } 66 \\
\text { PB) }\end{array}$ & Dedicação & & $\begin{array}{l}\text { Um homem conversando com } \\
\text { várias pessoas sentadas no } \\
\text { chão (foto } 43 \mathrm{~PB} \text { ) }\end{array}$ & Liderança \\
\hline & $\begin{array}{l}\text { Cinco homens de terno em } \\
\text { volta de uma mesa com um } \\
\text { notebook em um ambiente } \\
\text { de negócios. (foto } 6 \mathrm{C} \text { ) }\end{array}$ & Senso de equipe & & $\begin{array}{l}\text { Um senhor esculpindo dois } \\
\text { rostos em argila (foto } 30 \mathrm{~PB} \text { ) }\end{array}$ & Senso crítico \\
\hline के & & & हैँ & $\begin{array}{l}\text { Homem reformando uma } \\
\text { parede esculpida em forma de } \\
\text { folhas (foto } 90 \mathrm{~PB} \text { ) }\end{array}$ & $\begin{array}{l}\text { Arte } \\
\text { Entretenimento }\end{array}$ \\
\hline
\end{tabular}

- $\mathrm{C}$ - foto colorida e PB - foto preto e branco 
Os profissionais de recursos humanos sustentam uma imagem do trabalho bastante atrelada aos atributos do trabalhador, o que se justifica por estarem mais envolvidos com recrutamento, seleção e treinamento, cujo domínio das habilidades requeridas do trabalhador se torna indispensável. Deste modo, a comunicação, a criatividade, a dedicação e o senso de pertencimento a uma equipe emergiram a partir da escolha de fotos de um recepcionista de hotel, um homem fazendo arranjos de flores, duas moças em aula de balé e homens reunidos em torno de um notebook. Os profissionais de qualificação também fizeram associações relativas às habilidades do trabalhador, destacando o aperfeiçoamento contínuo (foto de uma mulher com livros a sua volta), liderança (um homem conversando com um grupo de pessoas sentadas ao chão) e senso crítico (um senhor idoso esculpindo rostos em argila), mas também a áreas de maior oferta e demanda de emprego, tais como a arte e o entretenimento (homem reformando uma parede).

O Quadro 2 ilustra algumas fotos escolhidas pelos grupos de professores da área de ciências humanas e exatas e as associações feitas.

\section{Quadro 2: Grupo 2, 3 e 4 - Professores Universitários das Áreas de Ciências Humanas e Exatas}

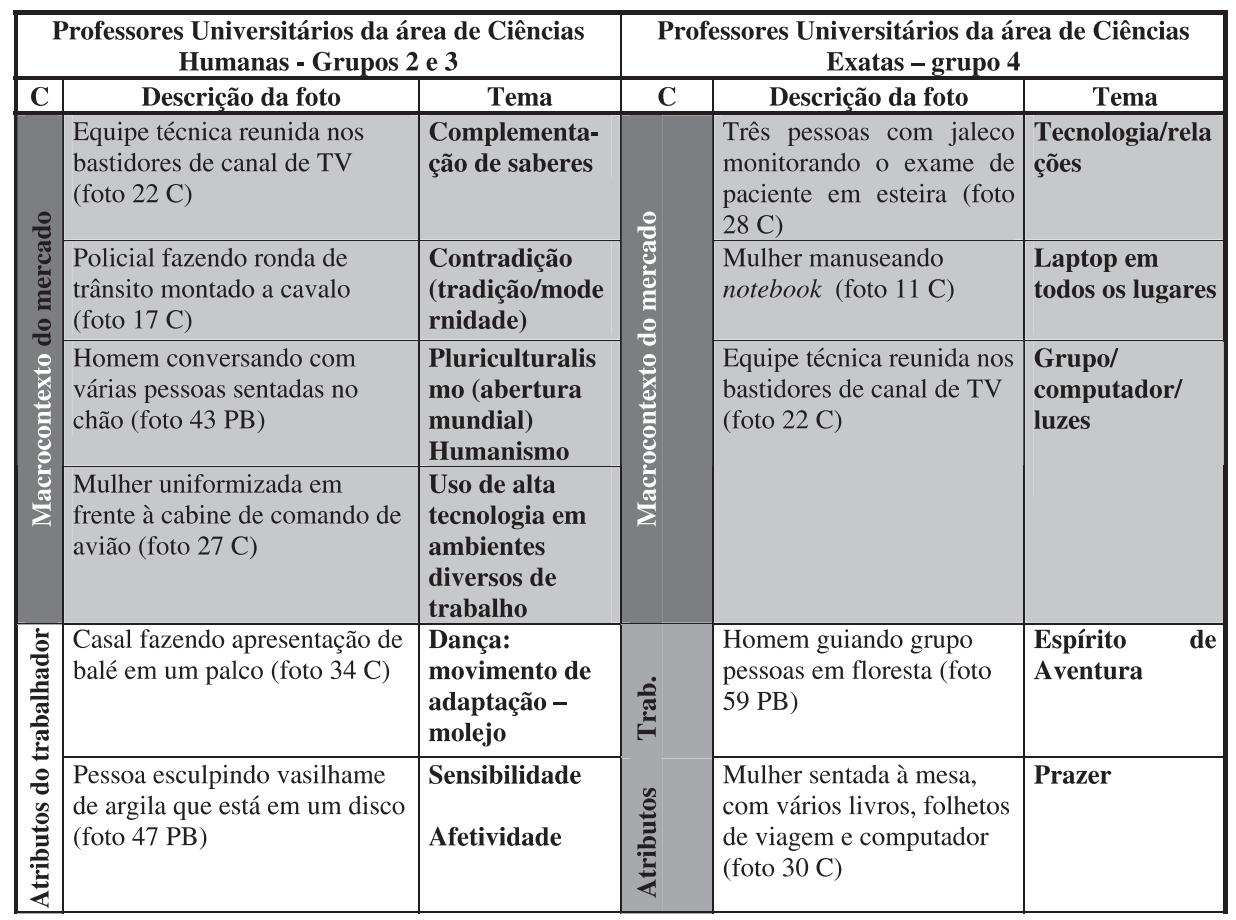




\section{(conclusão) \\ Quadro 2: Grupo 2, 3 e 4 - Professores Universitários das Áreas de Ciências Humanas e Exatas}

\begin{tabular}{|c|c|c|c|c|c|}
\hline \multicolumn{3}{|c|}{$\begin{array}{c}\text { Professores Universitários da área de Ciências } \\
\text { Humanas - Grupos } 2 \text { e } 3\end{array}$} & \multicolumn{3}{|c|}{$\begin{array}{c}\text { Professores Universitários da área de Ciências } \\
\text { Exatas - grupo } 4\end{array}$} \\
\hline $\mathbf{C}$ & Descrição da foto & Tema & $\mathbf{C}$ & Descrição da foto & Tema \\
\hline 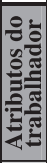 & $\begin{array}{l}\text { Homem debruçado sobre mesa } \\
\text { na qual estão três xícaras de } \\
\text { café e vários gráficos. Outra } \\
\text { pessoa sentada faz anotações } \\
\text { em caderno (foto } 21 \mathrm{C} \text { ) }\end{array}$ & $\begin{array}{l}\text { Diálogo e } \\
\text { interlocução }\end{array}$ & \multirow{2}{*}{$\ddot{\Xi}$} & $\begin{array}{l}\text { Curral com muitas vacas e } \\
\text { homem fazendo a limpeza }\end{array}$ & $\begin{array}{l}\text { Fazenda: } \\
\text { produção de } \\
\text { alimentos/ } \\
\text { agricultor }\end{array}$ \\
\hline 节 & $\begin{array}{l}\text { Três pessoas com jaleco } \\
\text { monitorando o exame de } \\
\text { paciente em esteira (foto } 28 \mathrm{C} \text { ) }\end{array}$ & Medicina & & $\begin{array}{l}\text { Funcionária de fast food } \\
\text { colocando batatas fritas } \\
\text { em vasilhame de papel } \\
\text { (foto } 26 \mathrm{C} \text { ) }\end{array}$ & $\begin{array}{l}\text { Serviços/ } \\
\text { Comércio }\end{array}$ \\
\hline
\end{tabular}

Os professores universitários das áreas de ciências humanas e de exatas, tanto quanto os profissionais de RH e de qualificação, visualizam o macrocontexto de trabalho associado à tecnologia (mulher pilotando avião, mulher diante de notebook e equipe técnica de televisão reunida), cuja evidência maior ocorre na área de saúde: monitoramento de teste físico. Introduzem novos aspectos da representação imagética do trabalho ao destacarem a contradição entre o tradicional e o moderno no mundo do trabalho, expressa na foto de um policial fazendo ronda a cavalo no trânsito de carros, e a foto de um homem conversando com grupo de pessoas sentadas no chão, esta última interpretada como humanismo e pluriculturalismo. Os professores da área de humanas trouxeram imagens de atributos do trabalhador relacionadas à dança e ao movimento (um casal de bailarinos); sensibilidade e afetividade (uma pessoa esculpindo um vaso em argila); e diálogo e interlocução (uma pessoa interagindo com outra na análise de registros documentais), enquanto os professores da área de exatas registraram o espírito de aventura (homem guiando grupo em floresta) e o prazer no exercício do trabalho (mulher com vários livros sobre a mesa). Para os professores de humanas, o setor de atuação profissional é o da medicina, enquanto os professores de exatas trouxeram o comércio/serviços (funcionária de fast food) e a pecuária (foto de curral com muitas vacas).

O Quadro 3 ilustra algumas fotos escolhidas pelos profissionais de baixa qualificação que atuam no mercado formal e informal e os sentidos e as representações associadas a elas. A imagem de que o trabalho na atualidade não faz distinção de gênero e ainda de que há uma diferenciação entre o trabalho escolarizado (dotado de sentido e de realização profissional) e o trabalho comum (apenas para garantir a sobrevivência), encontra-se presente nas representações de macrocontexto dos profissionais de baixa qualificação. Aliás, este foi um fator de diferenciação dos demais grupos focais, cujos integrantes eram todos de nível superior. A constatação de que o negro exerce atividades pouco qualificadas também está no imaginário do trabalhador informal de baixa escolarização. A associação entre tecnologia e o 
trabalho na atualidade também não deixou de ser considerada pelos integrantes desses dois grupos focais; mas, enquanto os trabalhadores formais visualizaram a tecnologia como substituto do trabalho humano, os trabalhadores informais destacaram o uso de equipamentos de proteção em ambientes de alta tecnologia. No que diz respeito aos atributos do trabalhador, as imagens estão associadas tanto aos profissionais liberais que estudaram e se dedicaram bastante para atingir esta condição privilegiada, quanto a atividades que exigem esforço físico - coragem para mudar a natureza (cortar uma árvore) e determinação (doma de leões) - e paciência (psicoterapeuta ouvindo paciente deitado no divã). É digno de nota apontar que, ao trazerem aspectos do setor de atuação profissional, os trabalhadores formais e informais deixaram transparecer, uma vez mais, os dois mundos do trabalho: real e ideal. O consultório médico/dentista figurou lado a lado com o pedreiro e o artesão.

\section{Quadro 3: Grupos 9 e 10 - Profissionais de Baixa Qualificação dos Mercados Formal e Informal}

\begin{tabular}{|c|c|c|c|c|c|}
\hline \multicolumn{3}{|c|}{$\begin{array}{c}\text { Profissionais de baixa qualificação que atuam no } \\
\text { mercado formal }\end{array}$} & \multicolumn{3}{|c|}{$\begin{array}{c}\text { Profissionais de baixa qualificação que atuam no } \\
\text { mercado informal }\end{array}$} \\
\hline $\mathrm{C}$ & Descrição da foto & Tema * & $\mathrm{C}$ & Descrição da foto & Tema * \\
\hline \multirow{4}{*}{ 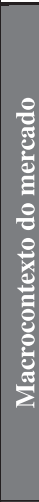 } & $\begin{array}{l}\text { Homem com avental sorrindo } \\
\text { e lavando panela na pia de } \\
\text { cozinha (foto } 18 \mathrm{C} \text { ) }\end{array}$ & $\begin{array}{l}\text { Homem } \\
\text { fazendo } \\
\text { trabalho de } \\
\text { mulher }\end{array}$ & \multirow{3}{*}{ 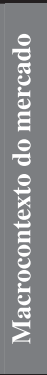 } & $\begin{array}{l}\text { Homem com avental sorrindo } \\
\text { e lavando panela na pia de } \\
\text { cozinha (foto } 18 \mathrm{C} \text { ) }\end{array}$ & $\begin{array}{l}\text { Homem } \\
\text { fazendo o que a } \\
\text { mulher faz }\end{array}$ \\
\hline & $\begin{array}{l}\text { Mulher vestida de macacão } \\
\text { limpando parede (foto 33 C) }\end{array}$ & $\begin{array}{l}\text { Mulher feliz } \\
\text { trabalhando } \\
\text { na limpeza }\end{array}$ & & $\begin{array}{l}\text { Mulher vestida de macacão } \\
\text { limpando parede (foto } 33 \text { C) }\end{array}$ & $\begin{array}{l}\text { O negro está } \\
\text { sempre nesta } \\
\text { função }\end{array}$ \\
\hline & $\begin{array}{l}\text { Alfaiate cortando calça (foto } \\
33 \mathrm{~PB} \text { ) }\end{array}$ & $\begin{array}{l}\text { Alfaiate } \\
\text { (tanto mulher } \\
\text { quanto } \\
\text { homem) }\end{array}$ & & $\begin{array}{l}\text { Dois homens com materiais } \\
\text { de proteção (luvas e capuz) } \\
\text { em ambiente de proteção de } \\
\text { alta tecnologia, fazendo } \\
\text { assepsia do local (foto } 3 \mathrm{C} \text { ) }\end{array}$ & $\begin{array}{l}\text { Homem } \\
\text { voltado para a } \\
\text { proteção }\end{array}$ \\
\hline & $\begin{array}{l}\text { Empilhadeira organizando } \\
\text { mercadorias em pátio de } \\
\text { empresa (foto 29 C) }\end{array}$ & $\begin{array}{l}\text { Empilhadeira } \\
\text { fazendo o } \\
\text { trabalho de } \\
10 \text { homens }\end{array}$ & \multirow{4}{*}{ 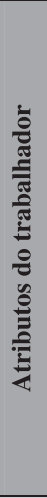 } & $\begin{array}{l}\text { Empilhadeira organizando } \\
\text { mercadorias em pátio de } \\
\text { empresa (foto } 29 \mathrm{C} \text { ) }\end{array}$ & $\begin{array}{l}\text { Aperfeiçoamen } \\
\text { to }\end{array}$ \\
\hline \multirow{2}{*}{$\frac{\mathscr{c}}{\mathscr{E}}$} & $\begin{array}{l}\text { Homem cortando árvore com } \\
\text { machado (foto } 18 \mathrm{~PB} \text { ) }\end{array}$ & $\begin{array}{l}\text { Coragem de } \\
\text { mudar a } \\
\text { natureza }\end{array}$ & & $\begin{array}{l}\text { Oftalmologista em consultório } \\
\text { junto a modernos } \\
\text { equipamentos (foto } 4 \mathrm{C} \text { ) }\end{array}$ & $\begin{array}{l}\text { Profissional } \\
\text { formado } \\
\text { ("batalhou } \\
\text { muito") }\end{array}$ \\
\hline & $\begin{array}{l}\text { Veterinário colocando } \\
\text { remédios nos olhos de } \\
\text { cachorro (foto } 89 \mathrm{~PB} \text { ) }\end{array}$ & $\begin{array}{l}\text { Dedicação ao } \\
\text { animal }\end{array}$ & & $\begin{array}{l}\text { Domador em jaula com } 4 \\
\text { leões (foto } 12 \mathrm{~PB} \text { ) }\end{array}$ & \begin{tabular}{|l} 
Muita \\
determinação \\
(matar um leão \\
por dia)
\end{tabular} \\
\hline \multirow{2}{*}{ ڤँ } & $\begin{array}{l}\text { Dentista com jaleco, proteção } \\
\text { ocular e bucal, usando } \\
\text { equipamento moderno no } \\
\text { dente do paciente (foto } 23 \mathrm{C} \text { ) } \\
\end{array}$ & Medicina & & $\begin{array}{l}\text { Psicoterapeuta sentado } \\
\text { ouvindo a paciente que está } \\
\text { deitada no divã (foto } 22 \mathrm{~PB} \text { ) }\end{array}$ & Paciência \\
\hline & $\begin{array}{l}\text { Senhor esculpindo dois rostos } \\
\text { em argila (foto } 30 \mathrm{~PB} \text { ) }\end{array}$ & $\begin{array}{l}\text { Construção } \\
\text { (arte) }\end{array}$ & 䒕 & $\begin{array}{l}\text { Pedreiro mexendo cimento } \\
\text { com pá (foto } 55 \mathrm{~PB} \text { ) }\end{array}$ & $\begin{array}{l}\text { Profissão muito } \\
\text { procurada }\end{array}$ \\
\hline
\end{tabular}

* Cerca de 5 ou 6 trabalhadores dos dois grupos solicitaram ajuda para registrar no papel o que estavam pensando, o que foi feito pela moderadora do grupo e as duas bolsistas de iniciação científica que estavam presentes na sala fazendo anotações da sessão de grupo focal. 
No Quadro 4 encontram-se algumas fotos escolhidas pelos grupos de profissionais das áreas de ciências humanas, exatas e da saúde, e os temas a elas relacionados. Nota-se que os participantes desses grupos enfatizaram muitos aspectos do macrocontexto. A tensão entre a democracia, o neoliberalismo e a transitoriedade de empregos (os políticos em volta de uma mesa), a rede (reunião de equipe técnica de televisão), a interdependência, a intensidade do volume de trabalho e sua extensão a todos os lugares (homens e mulheres manuseando notebooks), competitividade (homens na bolsa de valores), a tecnologia especializada (oftalmologista em consultório) e a preocupação ecológica (homem guiando um grupo de pessoas na floresta), tudo isto ilustra os temas referidos nesta categoria mais ampla. Observa-se, mais uma vez, a tendência de aqueles da área de humanas ressaltarem alguns atributos específicos do trabalhador: a sensibilidade e a emoção do trabalho, presentes, por exemplo, na foto do casal dançando balé. A novidade fica por conta da imagem do efêmero, trazida pela foto que retrata um desfile de modas. Os profissionais de exatas trazem imagens do trabalhador capaz de afirmar sua competência (homem mostrando cartaz de anúncio), que possui um conhecimento especializado (homem com capacete em estação de eletricidade) e apresenta boa capacidade de comunicação (recepcionista de hotel). Por fim, os profissionais da área de saúde enfocam a imagem da habilidade manual (pessoa esculpindo em argila), a atenção ao detalhe e a minúcia (homem compondo mosaico) e a necessidade de haver coordenação no trabalho (homem guiando grupo de pessoas na floresta). Os setores de atuação profissional foram mencionados por todos os três grupos focais, mas não necessariamente próximos das suas respectivas áreas de interesse e de formação. Os profissionais de saúde têm em mente o setor de fiscalização sanitária, os de exatas lembram o atendimento na área de saúde e os profissionais de humanas, os serviços em geral (bares). 


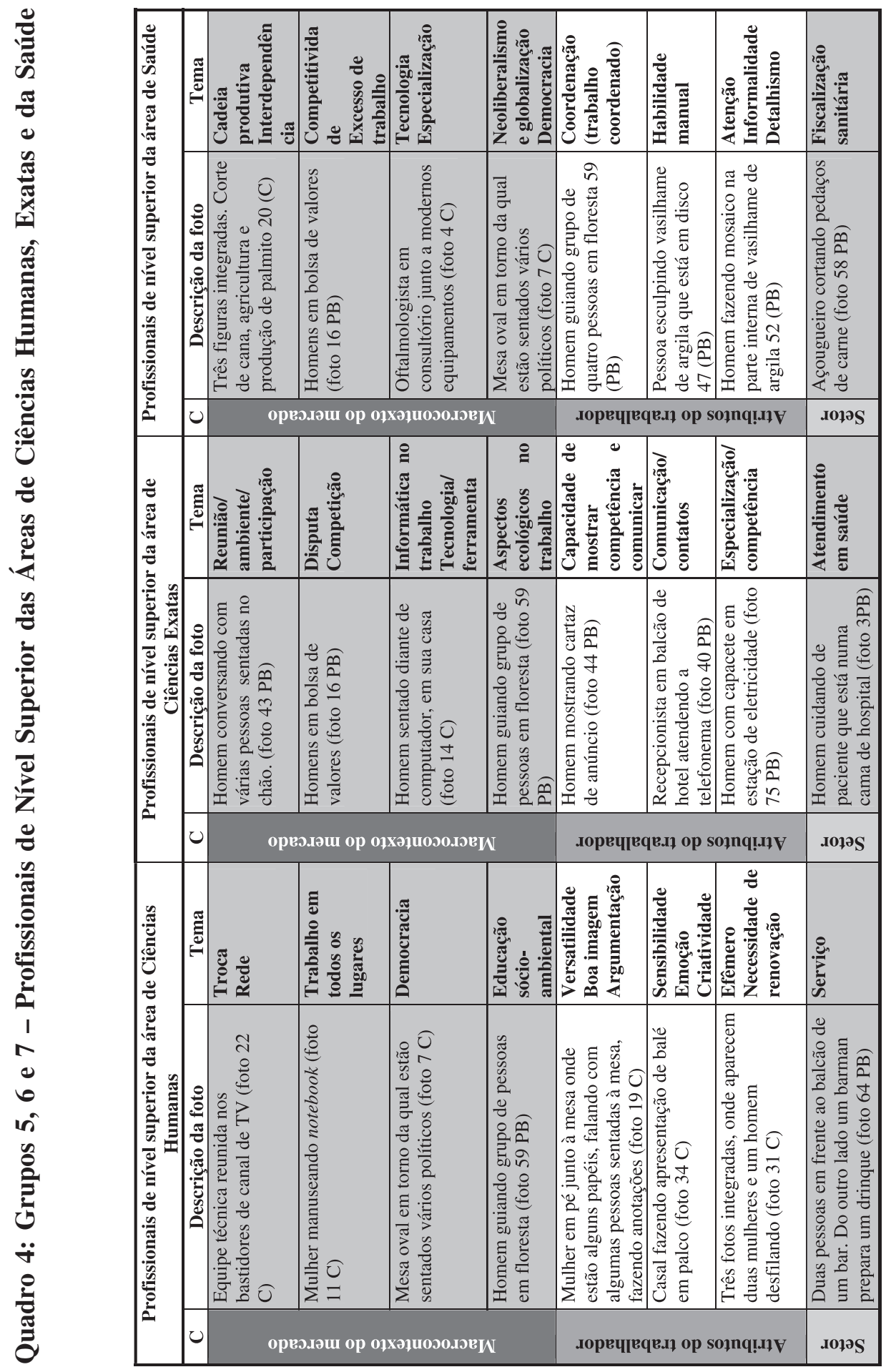




\section{Semelhanças e Diferenças na Imagem do Trabalho}

O processo de comparação das diversas categorias temáticas, relacionadas a cada um dos grupos sociais que participaram da pesquisa, faz emergir as semelhanças e as diferenças nas atribuições de significados às fotos apresentadas como modelo, permitindo elucidar as imagens do trabalho que os caracterizam como grupos distintos ou que os torna uma unidade mais ampla, ao compartilhar uma imagem homogênea do mundo do trabalho.

Como se afirmou na parte inicial deste artigo, partiu-se da premissa de que o lugar que se ocupa no mundo do trabalho, em termos de papéis profissionais, de algum modo interfere na maneira como se constrói a imagem do trabalho. Apesar de a oferta de modelos representativos do trabalho ter sido muito diversificada, principalmente a de fotos preto e branco, há indícios de que algumas delas parecem ser mais marcantes nas imagens que as pessoas têm do trabalho, independentemente do lugar em que se encontram; mas as diferenças aparecem no enfoque dado a esta mesma representação imagética por grupos sociais distintos.

A ênfase na escolha de fotos em que apareciam pessoas reunidas ou em interação é componente importante das imagens do trabalho na atualidade, embora tenham sido expressas de modo diferenciado nos grupos focais. A foto de políticos sentados em torno de ampla mesa oval, por exemplo, suscitou imagens de macrocontexto no grupo de profissionais de Recursos Humanos (acordos), nos profissionais da área de humanas (democracia) e nos profissionais da área de saúde (neoliberalismo, globalização e democracia). A foto da equipe técnica de TV em torno de uma mesa, deliberando sobre questões de trabalho, trouxe, para o grupo de professores da área de humanas, a imagem da complementação dos saberes, o que permite inferir que tal complementaridade é obtida pelas trocas interpessoais no interior de uma equipe, significado bastante semelhante ao da imagem dos profissionais da área de ciências humanas, que associaram a mesma foto a redes e trocas nas relações de trabalho. Para o grupo de profissionais que atuam na qualificação de trabalhadores a mesma foto da equipe técnica trouxe à tona a imagem da gestão participativa.

A foto de homens na bolsa de valores trouxe representações imagéticas comuns a alguns grupos: a da competitividade e da disputa para os profissionais da área de exatas, e a da pressão para tomada de decisão para os profissionais que atuam na qualificação de trabalhadores. Os profissionais da área de saúde, no entanto, talvez por viverem situações de estresse semelhante ao de trabalhadores em bolsa de valores, acrescentaram a essa foto mais um sentido, o do excesso de trabalho.

Em consonância com as discussões de macrocontexto, a questão da imagem de pessoas em grupo aparece novamente como bastante característica do mundo 
do trabalho atual; mas usando outra linha de argumentação: a favor da necessidade de o trabalhador dispor de habilidades que lhe permitam trabalhar e se relacionar em equipes, particularmente uma preocupação que é frequiente entre profissionais que atuam em recrutamento e seleção de pessoas, cujo ponto de partida é a definição das competências dos profissionais demandadas pela organização.

A imagem de liderança, que guarda semelhança com a questão de grupos de trabalho, também foi mencionada no grupo de profissionais que atuam na qualificação de trabalhadores, igualmente preocupados com o perfil do trabalhador, por causa da sua responsabilidade na elaboração de programas que aumentem as chances de inserção no mercado de trabalho. A foto do homem que guia um grupo de pessoas em uma caminhada da floresta esteve associada a três sentidos: o de espírito de aventura (atributos) para o grupo de professores da área de exatas; ao de habilidades de coordenação (atributos) para os profissionais da área de saúde; e à educação socioambiental (macrocontexto) para o grupo de profissionais da área de humanas.

Ao dirigir a análise para os dois grupos de trabalhadores de baixa qualificação, evidenciam-se aspectos importantes a serem comentados. Um deles é o de que praticamente não foram selecionadas fotos de pessoas em contexto de grupo, mas apenas duas em situação de interação interpessoal, a do psicoterapeuta com um paciente, e a de dois homens trabalhando em fábrica de alta tecnologia com equipamentos de segurança. A maioria das fotos escolhidas foi de uma pessoa exercendo alguma atividade concreta (cortando árvore, recortando uma calça, fazendo massa de cimento, colocando remédio no cachorro, esculpindo, empilhando caixas etc.).

Houve, no entanto, muita similaridade nas fotos escolhidas pelos dois grupos, quando comparados aos outros grupos de nível de instrução superior. Exceto as fotos do oftalmologista em seu consultório, rodeado de modernos equipamentos, também escolhida por profissionais da área de saúde e de RH, e a do senhor idoso esculpindo dois rostos em argila, selecionada pelos participantes do grupo que atua na qualificação de trabalhadores, as outras fotos foram distintas, sem contar que o sentido atribuído a elas foi diversificado. Para o trabalhador informal, a imagem do oftalmologista é a daquele profissional 'formado, que batalhou muito', que por ter um nível de escolaridade mais alto (atributo) galgou uma posição privilegiada no mercado de trabalho, sem destacar a questão da tecnologia, tal como nos dois grupos de nível superior, cujos membros escolheram a mesma foto. O senhor idoso esculpindo rostos em argila trouxe a imagem do setor de construção civil, com destaque para o sentido de que neste tipo de trabalho a pessoa pode desenvolver sua arte, enquanto no grupo de profissionais que atuam na qualificação de trabalhadores a imagem esteve associada ao senso crítico como atributo fundamental do trabalhador atual. 
É digno de nota apontar também que a imagem do trabalho atrelada a gênero se apresentou forte nos dois grupos de trabalhadores formais e informais, o que não emergiu nos outros grupos. O homem vestido de avental sorrindo ao lavar panelas na cozinha apareceu em ambos os grupos, suscitando imagens de macrocontexto: 'o homem fazendo trabalho de mulher'. O alfaiate fazendo o recorte de uma calça também suscitou no grupo de trabalhadores formais a imagem de ausência de distinção no mundo do trabalho atual de atividades femininas e masculinas. Se de um lado, ambos se distanciam de uma imagem de discriminação de gênero, de outro os trabalhadores informais imaginam haver discriminação racial, sinalizando que para o negro são reservadas funções pouco valorizadas (mulher negra vestida de macacão limpando parede).

Um último aspecto que merece menção é o da foto da empilhadeira, também escolhida pelos trabalhadores formais e informais; mas, enquanto os trabalhadores formais a visualizam de modo negativo, interpretando a tecnologia como substituta do trabalho humano, causadora de desemprego, os trabalhadores informais a interpretaram como algo inevitável que torna necessário que o homem se aperfeiçoe para lidar com novas exigências de trabalho. Se os trabalhadores formais destacam as imagens da medicina e da construção civil no mundo do trabalho atual, os trabalhadores informais apontam a importância da profissão de pedreiro neste mesmo cenário.

\section{CONSIDERAÇÕES FINAIS}

Embora nem todas as fotos escolhidas pelos participantes dos diversos grupos tenham sido analisadas neste artigo e as autoras não ignorem que as fotos apresentadas estejam longe de esgotar todas as possibilidades de representação imagética do tema, torna-se possível apontar algumas conclusões. A primeira delas se refere à nítida diferenciação entre as representações de trabalhadores de nível superior (grupos de professores, qualificadores e profissionais) daquelas dos trabalhadores de baixa escolarização e qualificação. Ainda que estes últimos hajam escolhido, em raras situações, as mesmas fotos, há visível diferenciação do sentido geral atribuído a elas. Os trabalhadores de baixa qualificação do mercado formal ou informal visualizam dois mundos do trabalho: 'o real', concreto, que é vivenciado por eles no cotidiano e que lhes assegura a sobrevivência, e o 'idealizado', acessível àqueles que estudaram e tiveram oportunidade para a realização pessoal. A rigor, isto não é um indício de desvalorização do próprio trabalho, pois em vários momentos do grupo de discussão eles afirmaram a importância de estarem desenvolvendo seu trabalho para sustentar a família e proporcionar estudo aos filhos (embora ressaltem também que os ganhos eram bastante insuficientes). O que é digno de nota é a 
importância que dão ao trabalho do profissional de nível superior. Em síntese, eles parecem admitir que o trabalho que realizam é valorizado (talvez porque tenham o trabalho como um valor), mas o trabalho realizado pelos escolarizados é bem melhor, apesar de não lhes ser acessível.

A segunda conclusão é a de que os participantes associaram as fotos a aspectos vinculados à realidade em que vivem, embora não se tenham restringido a ela. Um exemplo disso ocorreu com o grupo de profissionais da área de saúde que, das 58 associações de imagem do trabalho, citou 27 vezes aspectos característicos do seu trabalho cotidiano, tais como trabalho em equipe, qualificação profissional, habilidade manual (em especial enfermeiros) e preocupação com detalhes.

Para finalizar, reconhece-se que, em se tratando de uma investigação de caráter exploratório, o escopo de generalização é bastante limitado. Há, no entanto, uma possibilidade de traçar um esboço teórico sobre como é construída a imagem do trabalho.

A despeito da posição que ocupamos no mundo do trabalho (formadores, qualificadores, profissionais de diversas áreas, trabalhadores formais e informais de baixa escolarização), estamos atentos a questões de macro e de microcontexto. Reconhecemos que há políticas mais amplas que influenciam o modo como vivenciamos e imaginamos o trabalho, tais como políticas econômicas, globalização, tecnologia, igualdade/desigualdade de oportunidades, tensão entre formação/ educação e mercado, assim como incorporamos, em menor ou maior grau, as habilidades e competências que são exigidas do trabalhador (habilidades interpessoais, comportamentais/atitudes, cognitivas, técnico-motoras). Mas, embora muita coisa tenha mudado no mundo do trabalho e tenhamos ao nosso dispor inúmeras inovações tecnológicas que permitiriam tornar o trabalho mais prazeroso e humano, ao delegar para a máquina a sua parte mais árdua, parece que não estamos sendo capazes de redirecionar a antiga e persistente imagem da ambivalência do homem em relação ao seu trabalho, que nos acompanha na história da civilização. $\mathrm{O}$ trabalho nos atrai e nos causa repulsa, nos desperta sentimentos de amor e também de ódio.

Além desta imagem ambivalente presente nas pessoas de mais escolaridade, os trabalhadores de baixa qualificação sustentam duas imagens, traduzidas em dois mundos do trabalho dicotômicos e talvez incomensuráveis: o do 'peão', produto do trabalho nobre, honesto e importante para a sociedade, mas mal remunerado e destinado àqueles que não tiveram oportunidade de progredir nos estudos, e o do 'doutor', o trabalho valorizado, bem remunerado e que permite a realização financeira e profissional.

Enfim, o uso das fotos, como recurso técnico de coleta de dados, trouxe uma vez mais à tona, sob um novo ângulo, as imagens da ambivalência e da duplicidade, 
que sugerem estarem em lados distintos os escolarizados e os não-escolarizados. O desafio é compreender o que faz com que, ao longo da experiência humana, o trabalho persista como atividade capaz de produzir uma imagem de realização pessoal e de frustração, de avanço tecnológico e de exploração, de criatividade e de tensão; enfim, de prazer e de sofrimento. Será que é isto que torna o trabalho verdadeiramente humano? Se a resposta for sim a esta pergunta, a nossa humanidade é a que nos torna aprisionados a viver paradoxalmente o sofrimento e o prazer.

\section{Artigo recebido em 31.10.2004. Aprovado em 18.04.2005.}

\section{Notas}

${ }^{1} \mathrm{O}$ conceito de mundo do trabalho inclui tanto as atividades materiais, produtivas, quanto os processos de criação cultural que se geram em torno da produção de vida (Ciavatta, 2002).

${ }^{2}$ As imagens utilizadas nessa etapa do grupo focal compõem o teste BBTr-Br - Teste de Fotos de Profissões - versão masculina, de Achtnich, que foi adaptado à realidade brasileira (Jacquemin, 2000).

\section{ReferênCIAS Bibliográficas}

Arendt, H. (1981).

A condição humana (R. Raposo, Trad.). São Paulo: Edusp. (Obra original publicada em 1958).

Ariés, P. (1981).

História social da criança e da família. Rio de Janeiro: Zahar editores.

Bardin, L. (1979).

Análise de conteúdo (L. A. Reto \& A. Pinheiro, Trad.). São Paulo: Edições 70, Livraria Martins Fontes (Obra original publicada em 1977).

Battaglia, F. (1958).

Filosofia do trabalho. São Paulo: Saraiva.
Bauer, M. W. (2002).

Análise de conteúdo clássica: uma revisão. In M. W. Bauer \& G. Gaskell (Orgs.). Pesquisa qualitativa com texto, imagem e som: um manual prático (pp. 189-217). (P.A. Guareschi, Trad.). Petrópolis: Vozes (Obra original publicada em 2000)

Brandão, M. (2002).

Impactos da perda do emprego e o papel da qualificação no processo de inserção no mercado de trabalho. Tese de doutorado, Faculdade de Educação, Universidade Federal da Bahia, Salvador, BA, Brasil. 
Ciavatta, M. (2002).

O mundo do trabalho em imagens: a fotografia como fonte histórica (Rio de Janeiro, 1900-1930). Rio de Janeiro: DP \&A.

Gondim, S. M. G. (2001).

Trabalho docente e valores: em questão as novas tecnologias de informação e comunicação. Estudos de Psicologia, 18(1), 46-57.

Gondim, S. M. G. (2002).

Grupos focais como técnica de investigação qualitativa: desafios metodológicos. Revista Cadernos de Psicologia e Educação Paidéia, 12(4), 149-161.

Iñiguez, L. (Coord.) (2004).

Manual de análise do discurso em ciências sociais. Petrópolis: Vozes.

Loizos, P. (2002).

Vídeo, filme e fotografia como documentos de pesquisa. In M. W. Bauer \& G. Gaskel (Orgs.). A pesquisa qualitativa com texto, imagem e som: um manual prático (pp. 137-155). (P.

A. Guareschi, Trad.). Petrópolis: Vozes. (Obra original publicada em 2000).

Leite, M. M. (1993).

Retratos de família: leitura da fotografia histórica. São Paulo: EDUSP.
Meleiro, A. (1997).

Novos modos de representação para os modelos teóricos para a estrutura da matéria. Recuperado em 31 janeiro, 2004, de http://www.facom.ufba.br/ pretextos/alessandra.html

Morgan, G. (1996).

Imagens da organização (C. Bergamini \& R. Coda, Trad.). São Paulo: Atlas. (Obra original publicada em 1996).

Morgan, D. L. (1997).

Focus group as qualitative research (Qualitative Research Methods Series, 16). London: Sage Publications.

Neiva-Silva, L., \&

Koller, S. (2002).

$\mathrm{O}$ uso da fotografia na pesquisa em psicologia. Estudos de Psicologia, 7(2), 237-250.

Santaella, L., \&

Nöth, W. (2005).

Imagem: cognição, semiótica $e$ mídia. São Paulo: Iluminuras (Obra original publicada em 2001).

Smith, C. (2000).

Content analyzing and narrative analysis. In H. T. Reis \& C. M. Judd (Eds.). Handbook of research methods in social and personality psychology (pp. 313-335). Cambridge: University Press. 